\title{
Uma estranha na sala de aula: interculturalidade, letramento literário e ensino
}

\author{
A stranger in the classroom: interculturality, literary reading and teaching \\ Una extraña en aula: interculturalidade, lectura literaria y enseñanza
}

Marcelo Medeiros da Silva*

\begin{abstract}
Resumo
Tendo em vista que o ensino de literatura em nosso país tem se centrado em autores e em obras nacionais, dando pouca relevância ao diálogo intercultural, neste trabalho procuramos pensar as relações entre letramento literário, interculturalidade e ensino. Para tanto, apresentamos uma proposta de abordagem para a sala de aula do poema "Museu", escrito pela poetisa polonesa Wisława Szymborska (1923-2012), bem como defendemos a necessidade da inclusão, por intermédio de traduções, de textos de autores estrangeiros em meio ao repertório de obras oferecidas aos alunos dentro das ações de promoção à leitura que são fomentadas pela escola. As reflexões apresentadas pautam-se nos estudos sobre letramento a partir de Street (2014) e, em especial, nos estudos acerca do letramento literário a partir das orientações didático-metodológicas de Cosson (2006) e de Colomer (2007). Às reflexões desses autores, acostamos as considerações de Candido (2004) a respeito da importância da literatura na formação dos sujeitos, razão por que ela constitui um dos direitos humanos que não pode ser negado a ninguém. Finalizamos o trabalho chamando atenção para a importância do enfoque intercultural nas aulas de literatura com vistas à ampliação do horizonte cultural de nossos alunos a partir do contato com textos pertencentes a outras culturas.
\end{abstract}

Palavras-chave: letramento literário, tradução, interculturalidade, Wisława Szymborska.

\begin{abstract}
Considering that literature teaching in our country has focused on authors and national works, giving little relevance to intercultural dialogue, this paper reflects on the relationships between literary literacy, interculturality and teaching. Therefore, we present an approach to the classroom that would include, through translation, texts written by foreign authors, specifically the Polish poet Wislawa Szymborska's "Museum", alongside the traditional methods of reading promotion already implemented in schools. The reflections presented have basis in studies on literacy from Street (2014) and, especially, in studies on literary literacy from the didactic-methodological guidelines of Cosson (2006) and Colomer (2007). Together with these considerations, we identify in the considerations of Candido (2004) the importance of literature in the formation of subjects, suggesting that it is a human right that should not be denied to anyone. Finally, we conclude by emphasizing the importance of an intercultural approach in literature classes in order to broaden the cultural horizon of our
\end{abstract}

\begin{abstract}
Resumen
Teniendo en cuenta que la enseñanza de literatura en nuestro país se ha centrado en autores y obras nacionales, ofreciendo poca relevancia al diálogo intercultural, en este trabajo buscamos pensar las relaciones entre alfabetismo literario, interculturalidad y enseñanza. Por tanto, presentamos una propuesta de abordaje para el aula del poema "Museo", escrito por la poetisa polaca Wislawa Szymborska (1923-2012), así como defendemos la necesidad de la inclusión, a través de traducciones, de textos de autores extranjeros en el repertorio de obras que se ofrecen a los alumnos dentro de las acciones de promoción a la lectura implementada por la escuela. Las reflexiones presentadas se basan en los estudios sobre la adquisición de lectura literaria a partir de Street (2014) y, en especial, en los estudios sobre tal competencia lectora literaria a partir de las orientaciones didácticometodológicas de Cosson (2006) y de Colomer (2007). A las reflexiones de estos autores, acatamos las consideraciones de Candido (2004) acerca de la importancia de la literatura en la formación de los sujetos, razón por la cual constituye uno de los derechos humanos que no
\end{abstract}

\footnotetext{
* Doutor em Letras e professor de Literatura do Centro de Ciências Humanas e Exatas, Universidade Estadual da Paraíba, Monteiro, PB, Brasil. (Dorcid.org/0000-0003-1055-910X. E-mail: marcelomedeiros_silva@yahoo.com.br.
} 
students through contact with texts belonging to other cultures.

Keywords: literary literacy, intercultural translation, Wisława Szymborska. puede ser negado a nadie. Por último, finalizamos el trabajo llamando la atención sobre la importancia del enfoque intercultural en las clases de literatura con miras a la ampliación del horizonte cultural de nuestros alumnos a partir del contacto con textos pertenecientes a otras culturas.

Palabras clave: lectura literaria, traducción intercultural, Wisława Szymborska.

\section{Introdução}

As pesquisas sobre o ensino de literatura centram-se, geralmente, em duas perspectivas: uma crítica, outra interventiva. Na primeira, as investigações têm apontado, comumente, os desacertos do ensino de literatura e as consequências para a formação de leitores. Na segunda, sem deixar de lado as críticas à forma como o processo de escolarização da literatura tem ocorrido em nossa educação básica, os trabalhos procuram apresentar alternativas que possam contribuir para um ensino de literatura que seja mais significativo para os alunos e que venha a contribuir, efetivamente, para a formação deles como leitores. Nesse caso, a ênfase é na apresentação de alternativas metodológicas para a abordagem do texto literário em sala de aula ou no compartilhamento de experiências/vivências exitosas no ensino de literatura.

Dentro da primeira perspectiva, ao longo de mais de duas décadas, muitos foram os estudos que radiografaram a escolarização da literatura tanto no ensino fundamental quanto no médio. De acordo com Alves (2014, p. 7), um desses primeiros trabalhos foi Literatura/ensino: uma problemática, de Maria Teresa Roco, que "diagnosticou várias questões relativas aos conteúdos ministrados na escola básica, bem como apontou questões de ordem metodológica". Na esteira dessa obra, discutindo problemas inerentes ao ensino de literatura e, ao mesmo tempo, propondo uma metodologia adequada ao trabalho com o texto literário, apareceu $A$ invasão da catedral: literatura e ensino em debate, de Ligia Chiappini Leite. Entretanto, é com a obra A formação do leitor: alternativas metodológicas, de Maria da Glória Bordini e Vera Teixeira de Aguiar, que encontraremos uma sistematização de métodos que, tomando o trabalho com o texto literário como eixo central, procuram contribuir para a formação de leitores mediante uma metodologia própria para a leitura de literatura a partir da escola.

Ainda dentro dessa perspectiva de investigação, que fez um diagnóstico crítico sobre o ensino de literatura na educação básica, muitas dissertações e teses, além de inúmeros artigos, foram escritas. Dentre os primeiros trabalhos do gênero, Alves (2014) estaca Crônica de uma utopia, de Maria Helena Martins, que, embora não tenha se pautado na vivência escolar, se assenta em um método que "privilegia não um saber a ser ensinado às crianças, [mas] antes [se centra no] acompanhamento e discussão do modo como [elas] se envolvem com determinadas obras e as significam" (Alves, 2014, p. 9). O quadro delineado por Alves (2014) encerra-se com menção aos Parâmetros Curriculares Nacionais e às Orientações Curriculares para o Ensino Médio, os quais, assim como os livros a que nos referimos acima, são frutos de, e/ou têm fomentado, pesquisas que procuram compreender como se dá o processo de formação de leitores na educação básica e quais as práticas de leitura e as metodologias empregadas em tal processo.

Por sua vez, os trabalhos que se pautam na segunda perspectiva, a de proposição de abordagens do texto literário para a sala de aula, têm reiterado a relevância da literatura como um dos repositórios dos bens culturais construídos pela humanidade e procuram mostrar que aquele que lê o texto literário pode reconhecer-se no Outro e, assim, criar vínculos com outras pessoas e, por extensão, com toda a humanidade, uma vez que o texto literário, importante elemento na criação da identidade do ser humano, contribui não só para a sua formação intelectual como também para a formação de sua personalidade, processo esse em que conhecimento e prazer podem se fundir. Por isso, tais trabalhos visam apresentar alternativas metodológicas que viabilizem que a presença 
da literatura na escola seja marcada pela fruição e que possam contribuir para que o ensino de literatura deixe de ser marcado por protocolos e convenções que têm mais distanciado os alunos do que propriamente aproximado os mesmos do texto literário.

Considerando-se as duas perspectivas apresentadas acerca do ensino de literatura, o presente trabalho assenta-se na segunda, uma vez que já existe uma vasta fortuna crítica sobre a primeira perspectiva. O nosso trabalho é, pois, uma proposta de ensino que tem como escopo a leitura de poesia. Centramo-nos nesse gênero em virtude do fato de que, passadas décadas desde que estudos já clássicos na área apontaram que a poesia é um gênero "menor" na formação de leitores, visto que, para muitos professores, trata-se de um gênero muito "difícil", essa situação ainda persiste, uma vez que a presença da poesia em sala de aula parece não ter maior relevo na formação dos alunos que a da prosa, ganhando apenas para o texto dramático que, em sala de aula, é tão esquecido quanto o texto poético. Tomar a poesia como um gênero cuja abordagem em sala de aula é tida como difícil tem sido utilizado, a nosso ver, como uma desculpa para um não "enfrentamento" do texto poético e para a consequente perpetuação da indiferença em relação à leitura de poesia no âmbito escolar, ainda que muitas experiências exitosas com tal gênero tenham ocorrido em escolas pelo país afora.

Tendo em vista que o ensino de literatura, conforme apontado nos estudos a que nos referimos em parágrafos anteriores, tem se centrado em autores e obras nacionais, dando pouca relevância ao diálogo intercultural, a proposta aqui apresentada volta-se para a leitura da poesia de uma autora estrangeira: Wisława Szymborska (Kórnik, 2 de julho de 1923 - Cracóvia, 1 de fevereiro de 2012), que acreditamos ser ainda desconhecida de nossos alunos e professores e cuja obra poderá contribuir para alargar os horizontes culturais e de expectativas de nossos alunos e, assim, redimensionar o ensino de literatura a partir de uma perspectiva pouco presente em nosso ensino: a interculturalidade. Em síntese, a nossa proposta de ensino centra-se nos estudos de letramento, em especial o do letramento literário, sob uma perspectiva intercultural a fim de garantir um ensino de literatura capaz de propiciar aos alunos uma formação humana mais ampla a partir do contato efetivo entre leitor e textos literários estrangeiros.

\section{Letramento literário e interculturalidade: considerações para a sala de aula}

Desde meados da década de 1980, os estudos sobre letramento passaram a impulsionar no Brasil ações que, tomando a escrita e, posteriormente, a leitura como ferramentas tecnológicas e culturais, visavam redimensionar o ensino básico. Tais estudos acentuaram o fato de leitura e escrita serem molas-mestras de sociedades letradas como a nossa, principalmente porque, nessas sociedades, ler e escrever se tornaram a porta de entrada do indivíduo ao universo do conhecimento e, portanto, constituem-se como um dos passos para a assimilação dos valores da sociedade, os quais estão, em sua maioria, registrados pelo código escrito. Por essa razão, as reflexões acerca da leitura e da escrita, quando associadas às relações entre exigências sociais e competências individuais, são inseridas nos estudos sobre letramento que se dividem em duas perspectivas: a do modelo autônomo e a do modelo ideológico.

No modelo autônomo, a tendência é centrar-se na dimensão técnica e individual. Nessa perspectiva, as práticas de leitura e de escrita são vistas como neutras, universais e livres das injunções culturais e das estruturas de poder que as configuram em um contexto social determinado. Esse modelo assenta-se em uma visão monolítica acerca do fenômeno do letramento e é reproduzido nos discursos que, desviando-se da complexidade e das reais dificuldades políticas que as questões de letramento suscitam, se centram:

nos casos apavorantes sobre o número de "analfabetos" tanto no Terceiro Mundo quanto em sociedades "avançadas"; [em] pressupostos paternalistas sobre o que significa ter dificuldades de leitura e de escrita na sociedade contemporânea; e [na] criação de falsas esperanças em torno do que significa a aquisição do letramento para perspectivas de trabalho, mobilidade social e realização pessoal (Street, 2014, p. 33). 
O modelo autônomo é criticado, sobretudo, porque restringe o letramento a "um conjunto de capacidades cognitivas, que pode ser medida nos sujeitos e [que é reiterado por expressões] como 'grau de letramento', 'nível de letramento' ou 'baixo letramento'". Centrando-se nas competências cognitivas individuais e tomando como parâmetro a relação do sujeito apenas com o texto escrito (Buzen, 2014, p. 9), a perspectiva do modelo autônomo comunga de uma concepção de letramento "como saberes sobre, situados nas pessoas, na cabeça das pessoas, para resolver problemas mediados pela escrita" (Dionísio, 2007, p. 212). Tal modelo deixa, pois, de lado as reflexões sobre "como as pessoas usam os textos e o que fazem com eles em diferentes contextos históricos e culturais" (Buzen, 2014, p. 9). Consequentemente, o modelo autônomo não consegue explicar "por que e como as diferenças específicas entre escrita e fala emergiram e foram reproduzidas em determinados contextos" (Street, 2014, p. 20). Até porque, partindo da língua e do discurso como práticas sociais, se "perguntarmos de que modo convenções particulares são criadas e reproduzidas em contextos específicos, talvez descubramos que existem situações em que o foco nas diferenças entre fala e escrita não é relevante para nosso entendimento da situação" (Street, 2014, p. 24). Enfim, "o foco num modelo autônomo de letramento desvia a atenção de variáveis mais complexas" (Street, 2014, p. 39).

Já no modelo ideológico, ao contrário do autônomo, o foco é a dimensão social da leitura e da escrita. Nesse caso, visto no plural e entendido como produto de práticas concretas e sociais, o letramento deve ser estudado em função da cultura, da história e dos discursos que fomentam tais práticas. Nessa outra perspectiva, "as práticas de leitura e de escrita estão sempre inseridas não só em significados culturais, mas em alegações ideológicas sobre o que conta como 'letramento' e nas relações de poder a ele associadas" (Bagno, 2014, p. 13). No modelo ideológico, o fenômeno do letramento é estudado a partir de um viés mais amplo que leva em conta "a natureza social da leitura e da escrita e o caráter múltiplo das práticas letradas, valendo-se de perspectivas transculturais" (Bagno, 2014, p. 13).

Desses dois modelos de letramento, o segundo é o que melhor se afina à proposta do presente trabalho, uma vez que aponta para o fato de que o letramento é um fenômeno singular cuja natureza, no entanto, é plural. Por essa razão devemos falar de letramentos e entendê-los como "um conjunto muito diversificado de práticas sociais situadas que envolvem sistemas de signos, como a escrita ou outras modalidades de linguagem, para gerar sentidos" (Rojo, 2009, p. 10).

Dentre as modalidades de linguagem existentes, centramo-nos, aqui, na linguagem literária não só porque nela, conforme afirma Lajolo (1999), a liberdade e o prazer são ilimitados, mas principalmente porque a literatura se configura como um complexo de textos que, de acordo com Eco (2003, p. 9), a humanidade produziu e produz não para fins práticos, mas por amor a si mesma. Como tal, esse complexo de textos a que chamamos literatura assume algumas funções para a nossa vida social e individual, atuando, mediante um saber literário consistente, na formação de sujeitos sociais, o que se coaduna com o enfoque intercultural que defendemos para o ensino de literatura.

Antes de prosseguirmos, esclareçamos que tomamos interculturalidade como um conjunto de práticas de convivência entre diferentes culturas, a partir do reconhecimento e da valorização da diversidade que as compõe, com vistas a propiciar a troca de experiências e o enriquecimento mútuo dos sujeitos. A interculturalidade serve-nos como ferramenta que, ao nos permitir fazer um confronto entre culturas as mais diversas, se configura como importante para darmo-nos conta da dialética de trocas entre as culturas (Pavis, 2015). Aqui, abramos um parêntesis para explicarmos, ainda que de forma breve, a perspectiva segundo a qual concebemos o termo cultura. Nesse sentido, acostamo-nos ao pensamento de Xidieh (1976, p. 35), para quem, de maneira geral, desconsiderando-se a posição teórica e os engajamentos políticos científicos daqueles que se voltam para os estudos de e sobre a cultura, esta tem sido definida como "um conjunto de traços e padrões materiais e espirituais, formulados socialmente, transmissíveis de geração a geração como meio de socialização e controle social". Esse é apenas um dos vários sentidos sobre o que é cultura. Se quisermos ampliar a lista, poderíamos dizer que: 
cultura está muito associada a estudo, educação, formação escolar. Por vezes se fala de cultura para se referir unicamente às manifestações artísticas, como o teatro, a música, a pintura, a escultura. Outras vezes, ao se falar na cultura de nossa época, ela é quase que identificada com os meios de comunicação de massa, tais como o rádio, o cinema, a televisão. Ou então cultura diz respeito às festas e cerimonias tradicionais, às lendas e crenças de um povo, ou a seu modo de se vestir, à sua comida, a seu idioma (Santos, 1986, p. 22).

Todavia, apesar da miríade de concepções sobre o que é cultura, podemos afirmar, a partir de Santos (1986), que as várias maneiras de conceber a cultura são tributárias de duas concepções. A primeira, de caráter mais geral, refere-se a todos os aspectos de uma realidade social. A segunda, mais restritiva, diz respeito especificamente ao conhecimento, às ideias e crenças de um povo. Na primeira concepção, cultura "diz respeito a tudo aquilo que caracteriza a existência social de um povo ou nação, ou então de grupos no interior de uma sociedade" (Santos, 1986, p. 24). Enfim, nessa perspectiva, a cultura procura dar conta das "características dos agrupamentos a que se refere, preocupando-se com a totalidade dessas características, digam elas respeito às maneiras de conceber e de organizar a vida social ou a seus aspectos materiais" (Santos, 1986, p. 24).

Na segunda concepção, que remete cultura a conhecimento, às ideias e crenças de um povo, o termo cultura circunscreve-se a uma esfera, a um domínio da vida social. Nesse sentido, cultura poderá fazer menção à língua, literatura, ao conhecimento filosófico, científico e artístico produzindo no seio de uma determinada sociedade. Definida assim, somos compelidos a pensar que a cultura é um fenômeno estanque, fechado, acabado e estagnado. Todavia, se várias são as definições sobre cultura, muitas das quais verdadeiramente antípodas, existe, pelo menos, ante o caos da impossibilidade de uma definição única, um consenso - as culturas humanas são dinâmicas e, portanto, marcadas pela própria heterogeneidade que singulariza o ser humano, daí por que o signo que melhor caracteriza a cultura seja o plural, que lhe acentua o seu caráter vário, e não o singular, que aponta para uma unidade e uniformidade que parecem não existir. Em outras palavras: "em vez de se falar em cultura como a totalidade de características, fala-se agora em cultura como uma totalidade de uma dimensão da sociedade" (Santos, 1986, p. 41).

Pelo exposto, a cultura, como manifestação de práticas e saberes de um povo, de um grupo, parece ser, por natureza, dinâmica, aspecto este que é potencializado quando uma cultura é posta em diálogo com outra, raiz essa de todo fenômeno intercultural, já que, no dizer de Canclini (2009 apud Justino, 2014, p. 114), a interculturalidade "remete à confrontação e ao entrelaçamento, àquilo que sucede quando os grupos entram em relações e trocas". Já no dizer de Justino (2014, p. 114), esse inter ao qual se prende o termo cultura(l) "implica diferença relacional e a consciência de relações sociais complexas, cujos parâmetros de diálogo não são exclusivamente e/ou, sobretudo, culturais". Logo, se a interculturalidade se define como o processo por meio do qual ocorre a interpenetração de culturas, sem o apagamento da identidade que singulariza uma cultura em relação a outra, a prática intercultural configura-se "mais que uma informação sobre as culturas, ela implica o desenvolvimento de atitudes positivas em respeito aos outros e à diversidade, e ela inclui finalmente a mudança cultural contínua sobre uma base igualitária" (Legault, 2000 apud Justino, 2014, p. 119).

Nesse sentido, acreditamos que trabalhar com literatura a partir de uma perspectiva intercultural poderá não só contribuir para a formação de leitores para quem o texto literário seja objeto de desejo, mas para a ampliação dos horizontes culturais desses leitores, uma vez que a literatura é "mais que um conhecimento, ela é a incorporação do outro em mim sem renúncia da minha própria identidade" (Cosson, 2006, p. 17). Sendo uma for ma específica de letramento, o letramento literário se configura como uma prática social que reflete relações de poder e possui uma condição especial em virtude da "própria condição de existência da escrita literária" (Cosson, 2006, p. 12).

Desse modo, o letramento literário, conforme o concebemos, deve ser visto como um conjunto de atividades que, tomando o texto literário como ponto de partida e de chegada, visa, sobretudo, contribuir para a leitura competente da linguagem literária, que dá forma a esses textos, a partir do aprimoramento da competência interpretativa dos alunos que não 
pode ficar circunscrita à leitura/interpretação apenas de textos pertencentes ao cânone nacional. Dentre as vantagens pedagógicas do amálgama entre letramento literário e interculturalidade, podemos apontar o fato de possibilitar que a educação literária, em particular, e a escolar, em geral, possa ser "reinventada" para "enfrentar as questões de um mundo complexo, desigual, diverso e plural" (Candau, 2012, p. 111).

O que nos faz advogar em favor da presença do enfoque intercultural nas aulas de literatura é o fato de que "a experiência literária não só nos permite saber da vida por meio da experiência do outro, como também vivenciar essas experiências" (Cosson, 2006, p. 17). Consequentemente, o texto literário é, por si só, uma ponte para diálogos interculturais, visto que ele é uma fonte em que vários saberes estão postos em diálogo, conforme assinalara Barthes (2007) há bastante tempo:

Num romance como Robinson Crusoé, há um saber histórico, geográfico, social (colonial), técnico, botânico, antropológico (Robinson passa da natureza à cultura). Se, por não sei que excesso de socialismo ou de barbárie, todas as nossas disciplinas devessem ser expulsas do ensino, exceto uma, é a disciplina literária que devesse ser salva, pois todas as ciências estão presentes no monumento literário. [...] a literatura faz girar os saberes, não fixa, não fetichiza nenhum deles; ela lhes dá um lugar indireto, e esse indireto é precioso. Por um lado, ela permite designar saberes possíveis - insuspeitos, irrealizados: a literatura trabalha nos interstícios da ciência: está atrasada ou adiantada com relação a esta [...]. A ciência é grosseira, a vida é sutil, e é para corrigir essa distância que a literatura nos importa. Por outro lado, o sabor que ela mobiliza nunca é inteiro nem derradeiro; a literatura não diz que sabe alguma coisa, mas que sabe de alguma coisa; ou melhor: que ela sabe algo das coisas que sabe muito sobre os homens (Barthes, 2007, p. 18-19).

Como mobilizador de saberes (inter)culturais, o texto literário seduz o outro, induz a gestos instauradores de autorias, desperta a consciência do sujeito para a necessidade de intervenções individuais e/ou coletivas, traz para perto do sujeito vivências as mais diversas, o que pode ser potencializado se, nas aulas de literatura, o repertório de textos que circulam não ficar restrito à produção nacional. Nesse caso, diante da impossibilidade de termos circulando, em sala de aula, textos em língua estrangeira, visto que o nosso sistema de ensino não tem possibilitado que o aluno conheça, proficientemente, outra língua que não a materna, acreditamos que o acesso a textos de outras culturas deve se dar por meio das traduções. Como é sabido, a tradução é uma prática cultural de extrema importância no intercâmbio entre saberes e no acesso a outros mundos que não o meu. Como prática cultural, a tradução implica:

um contato cultural profundo entre duas ou mais culturas. Aproximar-se e deixar-se tocar pelo desconhecido, mesmo correndo-se o risco do enfrentamento, do conflito, parece ser uma maneira mais profícua e certamente mais trabalhosa de tradução cultural (Borges e Nercolini, 2002, s/p).

Em outras palavras, a tradução, mais do que uma operação linguística, atua como operação cultural, visto que:

Traduzir é, ao mesmo tempo, habitar a língua do estrangeiro e dar hospitalidade a esse estrangeiro no coração de sua própria língua. Da mesma maneira, será que não podemos dizer que a memória e a história traduzem aquilo que foi transmitido do acontecimento na língua de acolhida do narrador? (Ricoeur, 1998 apud Oustinoff, 2011, p. 127).

Como operação cultural, a tradução impulsiona o intercâmbio entre culturas distintas, fomentando o estabelecimento de relações comerciais, políticas, sociais bem como a troca de bens simbólicos, o que, especialmente nesse último caso, é imprescindível para a formação de nossos alunos, razão por que as traduções devem, a nosso ver, ser incorporadas ao conjunto de textos a que precisam ter acesso os alunos nas atividades de promoção à leitura desenvolvidas pela escola.

\section{Uma visita ao Museu: procedimentos de leitura para a sala de aula}

O poema escolhido, "Museu", de Wisława Szymborska, foi vivenciado em uma das aulas que ministramos na disciplina sobre literatura e ensino do mestrado profissional em formação de 
professores da Universidade Estadual da Paraíba. Na ocasião, os textos teóricos a serem debatidos pelos alunos/as, muitos/as dos quais professores/as na rede pública de ensino, versavam sobre procedimentos gerais para a abordagem da literatura em sala de aula. Especificamente, tratávamos na ocasião do que propunham Cosson (2006) e Colomer (2007). Por isso, a título de ilustração, escolhemos o referido poema para mostrar aos alunos da disciplina como o que os textos teóricos sugeriam podia ser viabilizado em sala de aula. Daí surgiu a proposta que passamos a apresentar a seguir, sobretudo como forma de tornar conhecida a poesia da poeta polonesa.

a) Em nossa experiência, como professor na graduação e como coordenador de um subprojeto para a formação de leitores na educação básica vinculado ao Programa de Bolsas de Iniciação à Docência (PIBID), temos comprovado que atividades motivacionais têm uma aceitação positiva por parte dos alunos. Aqui, é preciso deixar claro que as atividades de motivação que antecedem o trabalho com o texto literário não são mero entretenimento. Os alunos precisavam entender que há uma relação entre o que se propôs como motivação e o que se virá mais à frente como objeto de uma reflexão mais detida, uma vez que, como pontua Cosson (2006), as atividades de motivação devem despertar a atenção dos alunos para a atividade a ser realizada posteriormente. Em outras palavras, tais atividades não se configuram como meros passatempos, mas, sim, como preparação necessária para que os alunos possam, de maneira prazerosa e interativa, ter um contato preliminar com aquilo que se deseja que eles estudem. Sendo assim, pensando no poema de Wisława Szymborska, sugerimos, como atividade motivacional, a realização da dinâmica conhecida como jogo da forca.

Nesse caso, o aluno precisa acertar qual é a palavra proposta. As dicas de que ele dispõe são o número de letras e o tema ligado à palavra a ser descoberta. A cada letra errada, é desenhada uma parte do corpo do enforcado. O jogo encerra-se quando a palavra é descoberta ou quando todas as partes do corpo do enforcado são completadas. Para começar o jogo, é feito o desenho de uma base e de um risco correspondente ao lugar de cada letra. Considerando-se que um dos objetivos da aula é apresentar a poeta polonesa, sugerimos que a palavra a ser descoberta pelos alunos seja o nome da própria poeta. Uma vez descoberta a palavra, pode-se fazer perguntas a fim de verificar se autora e a obra são de conhecimento de nossos alunos.

b) Partindo-se do pressuposto de que os alunos não conhecem Wisława Szymborska, pode-se passar para uma próxima etapa: fazer uma breve introdução sobre a poeta e sua poesia. Para tanto, o professor pode se basear no prefácio à obra "Poemas", que foi publicada no Brasil pela Companhia das Letras e traduzida direto do polonês por Regina Przybycien. Se preferir, podem ser exibidas algumas fotos da autora e do seu país de origem. Aqui, pode ser um bom momento para uma aproximação cultural entre o país da poeta e o dos alunos leitores dos poemas dela via tradução. Aspectos históricos e geográficos, além, é claro, de elementos próprios da cultura de cada país, podem nortear esse momento em que o contato com a cultura do outro deve ser o escopo, inclusive para comparações com a própria cultura brasileira.

c) Após esse momento, tendo em vista que os procedimentos aqui foram pensados apenas para um único poema, o professor pode instigar a curiosidade dos alunos a fazer inferências a partir do título do texto a ser lido. Sendo assim, pensamos que alunos podem ser levados a responder perguntas como: O que é um museu? Qual a utilidade de um museu? Se você fosse criar um museu, que objetos recolheria? Você já esteve em um museu? Como foi essa experiência?

d) Feitas essas atividades, é preciso reafirmar o óbvio: realizar aquela que é a mais importante atividade em se tratando de formação de leitores - a leitura do texto em sua totalidade. É, pois, o momento de entregar uma cópia do poema aos alunos, o qual transcrevemos abaixo em tradução de Regina Przybycien:

Museu

Há pratos, mas falta apetite.

Há alianças, mas o amor recíproco se foi

há pelo menos trezentos anos.

Há um leque - onde os rubores? 
Há espadas - onde a ira?

E o alaúde nem ressoa na hora sombria.

Por falta de eternidade

juntaram dez mil velharias.

Um bedel bolorento tira um doce cochilo,

o bigode pendido sobre a vitrine.

Metais, argila, pluma de pássaro

triunfam silenciosos no tempo.

Só dá risadinhas a presilha da jovem risonha do Egito.

A coroa sobreviveu à cabeça.

A mão perdeu para a luva.

A bota direita derrotou a perna.

Quanto a mim, vou vivendo, acreditem.

Minha competição com o vestido continua.

E que teimosia a dele!

E como ele adoraria sobreviver! (Szymborska, 2011, p. 31)

Sugerimos que, para esse momento de leitura, como se faz necessário um contato íntimo do leitor com o próprio texto, visto que, no dizer de Cosson (2006), ler é um ato solitário e solidário, é preciso que seja feita uma leitura silenciosa do poema. Após, o poema deve ser lido mais uma vez. Só que agora deve ser em voz alta. O professor pode escolher como melhor ele conduzirá a realização dessa leitura. A nosso ver, é importante que todos os alunos participem dela. Por isso, se observarmos as duas primeiras estrofes, talvez elas se permitam ser lidas como se fossem parte de um jogral. Nesse caso, as demais estrofes poderão ser lidas apenas por um único aluno ou por um aluno diferente para cada estrofe, ou até mesmo o professor pode lê-las, embora acreditemos que este deva ser um momento para o aluno ir testando as possibilidades de encantamentos que podem ser despertados a partir da leitura oral do texto. Afinal, como afirma Alves (2016):

A leitura oral é sempre um momento central da experiência com a poesia. Daí a necessidade de retomada do texto por diferentes leitores. Inúmeros são os poemas que são melhor acolhidos e compreendidos apenas depois de algumas vocalizações. A questão da leitura oral liga-se a uma necessidade de acordarmos para a importância da voz. Minha voz, voz do outro são instrumentos que transmitem emoções e percepções as mais diversas (Alves, 2016, p. 218).

Ainda acerca da importância da realização oral do poema, Alves (2016) reitera as palavras de Zumthor (1997), para quem:

As emoções mais intensas suscitam o som da voz, raramente a linguagem: além ou aquém destas, murmúrio ou grito, imediatamente implantado nos dinamismos elementares. Grito natal, grito de crianças em seus jogos ou aquele provocado por uma perda irreparável, uma felicidade indizível, um grito de guerra que, em toda sua força, aspira fazer-se canto. Voz plena, negação de toda redundância, explosão do ser em direção à origem perdida - ao tempo da voz sem palavra (Zumthor, 1997, p. 13).

Caso queira fazer com que os alunos comparem a leitura que realizaram do poema com outras já realizadas, o professor pode optar por passar um vídeo em que o poema em questão aparece sendo lido. ${ }^{1}$ Aqui, sugerimos que a leitura realizada pelos alunos seja gravada e, depois, se proceda a uma comparação entre a leitura que eles fizeram e a que aparece no vídeo. A discussão, nesse caso, não deve se pautar por julgamentos de valor do tipo melhor ou pior, mas levar os alunos a pensar nas potencialidades diversas que a realização oral de

\footnotetext{
${ }^{1} \mathrm{O}$ vídeo a que nos referimos encontra-se no seguinte link: https://www.youtube.com/watch?v=g5zJEfqnPfk
} 
um poema pode ter e as emoções que uma ou outra palavra, ditas de uma ou outra forma, acompanhadas de um ou outro gesto, podem nos despertar.

e) Finda a leitura do texto, deve ser aberto um espaço para a troca de impressões de leitura. Nesse momento, o professor estimulará os alunos a falarem sobre o que acharam do poema. Este os agradou? Por quê? Que passagens do poema mais tocaram os alunos? Por quê? Que verso chamou a atenção? Por que chamou a atenção? Existe algum verso "obscuro"? Alguma palavra desconhecida? Atentar para o fato de que o poema se inicia com uma voz aparentemente distante, como se o sujeito que fala não quisesse se revelar, mas se revela na estrofe final quando diz que, no embate entre ele e o vestido, ele, a voz lírica, há de ainda permanecer como vencedora. Aqui, o professor pode abrir espaço para tecer considerações acerca do gênero a que pertence essa voz: masculino? Feminino? Pode ser esse o momento para se discutir um pouco o lugar que o feminino ocupa na lírica de Wisława Szymborska.

f) Terminada essa etapa de "análise/interpretação" do poema, o ideal seria que o professor trouxesse para os alunos outros poemas da poeta a fim de aprofundar o contato dos alunos com sua obra e com os seus aspectos formais e temáticos. Entretanto, caso não queira realizar essa etapa, ele poderá passar para a seguinte e realizar o que sugerimos aqui como etapa final.

g) Como a nossa proposta se baseia na importância do alargamento do horizonte cultural dos alunos a partir não só do conhecimento de textos e autores pertencentes a outras culturas, como também da comparação deles com obras e autores nacionais, o professor deverá trazer para a sala de aula textos da literatura brasileira que possam dialogar com a poesia de Wisława Szymborska. Antes, o professor procurará sondar se o texto lido remete os alunos a outros textos. Caso os alunos apontem outras criações análogas ao poema de Szymborska, essas devem ser lidas em sala de aula para que se perceba a pertinência do diálogo entre os textos. Caso os alunos não consigam apontar outros textos que dialoguem com o da poeta polonesa, sugerimos que sejam levados poemas do poeta Carlos Drummond de Andrade. Tendo em vista que escolhemos de Szymborska o poema "Museu", indicamos para uma leitura comparativa o poema "Cerâmica", de Drummond:

\section{CERÂMICA}

Os cacos da vida, colados, formam uma estranha xícara.

Sem uso, ela nos espia do aparador (Andrade, 2015, p. 363).

O texto acima deve ter a mesma atenção, em sala de aula, que dedicamos ao poema da poeta polonesa. Por isso, antes mesmo de estabelecermos um exercício comparativo entre ele e o de Szymborska, o poema de Drummond merece ser abordado a partir de procedimentos específicos para ele, os quais podem ser semelhantes aos empregados anteriormente. Assim, faz-se necessária uma motivação que prepare os alunos para receber o poema. Sugerimos que o professor escolha uma cerâmica ilustrada para levar para sala de aula. Como a cerâmica deverá estar quebrada, deve-se pedir aos alunos que a reconstruam. A partir daí, diante da peça que, reconstruída, permanece quebrada, os alunos devem ser levados a pensar sobre: a) o que aconteceu com a cerâmica?; b) ela perdeu o valor?; c) vale a pena reconstruí-la?; d) como isso poderá ser feito? Após esse momento de reflexão, achamos pertinente que seja entregue a eles um texto sobre Kintsukuroi, uma técnica japonesa para a restauração de objetos de porcelana. ${ }^{2}$

Logo em seguida, o professor deve escrever as palavras-chave do poema (cerâmica, xícara, cacos, aparadouro, vida) na lousa e pedir que os alunos produzam uma pequena história envolvendo tais palavras. Depois de socializadas as histórias criadas pela turma, com uma discussão acerca do que motivou cada aluno a escrever a história que escreveu, o professor

\footnotetext{
${ }^{2} \mathrm{O}$ docente pode se utilizar dos textos presentes no blog "Pense e Sonhe. Viva!" (https://bit.ly/2Z0IqzF) ou no site "Sedentário Hiperativo" (https://bit.ly/2U6H3M7)
} 
entregará uma cópia do poema "Cerâmica", de Carlos Drummond de Andrade. Uma vez lido o texto, inicialmente em silêncio, depois oralmente, e feita a discussão acerca das impressões dos alunos sobre o poema, o professor deve levar os alunos ao exercício comparativo entre o poema de Drummond e o de Szymborska. O que há de comum? O que há de diferente? Como as experiências de vida plasmadas nos textos se tocam ou se distanciam?

Para além da leitura dos dois poemas indicados, as aproximações interculturais podem ser realizadas pelos alunos a partir da investigação de temáticas que são recorrentes na poesia da poeta polonesa e do poeta brasileiro. Duas temáticas permitem a aproximação entre os dois autores: a de cunho existencial e a da guerra. Com isso, os alunos poderão refletir até que ponto essas temáticas podem levá-los a reconhecer e a compreender os mesmos sentimentos em autores diferentes:

La literatura, sin duda alguna, puede ayudar a encontrar elementos comunes de identificación y, por tanto, hacer visible y tomar consciencia que son muchos más los referentes que compartimos que los que nos diferencian. Los alumnos jóvenes en general y los de segundas lenguas en particular, debido a la falta de experiencias personales, frecuentemente muestran una actitud marcadas por prejuicios hacia lo desconocido podrán reconocer a través de la literatura que los referentes sobre los se pivota nuestra propia identidad es compartida y sentida por un gran número de personas. En este sentido, apoyo la opinión de Sabariego Puig (2004), "la misma introspección crítica y respetuosa con la cultura propia nos permitirá ser también respetuosos y críticos con los demás" (Leibrandt, 2006, p. 3).

Em outras palavras, os poemas sugeridos aqui como objeto de leitura intercultural podem ver vistos como portadores de informações que nos levam a por em contato campos como a cultura, a política, a história:

Sumergiendo al alumno/lector en las obras literárias él llega a conocer el mundo íntimo de las figuras, lo que piensan, sueñan, de lo que hablan y sus problemas pudiendo establecer relaciones con temas que ofrecen una visión política y social del otro país que a su vez puedan contrastar con el suyo propio (Leibrandt, 2006, p. 3).

Como objeto cultural, a literatura, ainda na esteira de Leibrandt (2006), é uma porta que permite a entrada do leitor a mundos até então desconhecidos, os quais passam a ser vistos a partir de múltiplas perspectivas e de suas próprias realidades igualmente diversas. Com isso, queremos pontuar que não é apenas com a leitura de textos estrangeiros que se pode por em diálogo saberes, visto que o texto literário permite um olhar não só para culturas de outros países, mas, sobretudo, sobre a própria cultura dos alunos. Assim, a percepção da pluralidade cultural como elemento importante em nossa formação poderia dar-se a partir do estudo de autores brasileiros e não apenas entre um autor brasileiro e outro de nacionalidade diferente. Ao propormos a entrada, em sala de aula, de textos de outras culturas, via tradução, estamos pleiteando o alargamento do repertório de textos e de autores/as que circulam nas práticas de leitura em língua materna e, portanto, colocar em diálogo textos pertencentes a culturas distintas, produzidos por sujeitos também distintos de forma que nesse processo de aproximação o aluno possa ter uma melhor compreensão de sua cultura, da cultura do outro e de si mesmo.

Além disso, tendo em conta que o objetivo principal de nossa proposta é tornar conhecida a poesia da poeta polonesa, a partir da qual o diálogo intercultural poderá ser estabelecido por meio de vieses distintos, outra atividade a ser realizada, conforme já sinalizamos antes, seria solicitar aos alunos que procurassem na internet outros poemas de Wislawa Szymborska. A intenção é que os alunos leiam um maior número de poemas dela em casa e tragam para a sala de aula aqueles de que mais gostaram. Feito isso, o espaço da sala de aula será dedicado à socialização dessas leituras, momento em que alguns poemas poderão ser escolhidos para uma leitura/análise mais pontual. A turma pode montar uma pequena antologia para circular entre si e entre outras turmas. Pode ser também organizado um sarau dedicado à poesia de Wislawa Szymborska. Além disso, considerando-se o poema que motivou a presente proposta, os alunos podem fazer uma pesquisa acerca dos museus, apresentar os resultados para a turma e, inclusive, organizar uma ida a um museu, já que, tradicionalmente, a vista a museus integra as atividades 
educativas de muitas escolas, "seja para complementar um conteúdo abordado em sala de aula, seja para incrementar o aporte cultural dos estudantes ou ainda como um momento de lazer e socialização" (Pugliese e Marandino, 2018, p. 119). Enfim, muitas são as vantagens formativas que uma visita a um museu pode propiciar aos alunos e aos próprios docentes. Encerrando esta secção, existe ainda a possibilidade de aprofundar a comparação entre Drummond e Szymborska mediante a leitura de outros poemas de ambos os autores e, disso, haver uma mostra sobre o Brasil e a Polônia a partir do que está representado em suas obras. Aqui, a criatividade fica a critério do professor e dos seus alunos.

\section{Considerações finais}

Para o leitor de nosso texto - especialmente professores e pesquisadores na área do ensino de literatura - não há novidade no que expusemos e propusemos aqui. Reconhecemos a importância do ensino de literatura para a formação de nossos alunos, visto que comungamos da perspectiva segundo a qual a literatura pode desencadear neles o processo de humanização, isto é, a confirmação de valores que são essenciais para nós como seres humanos:

como o exercício da reflexão, a aquisição do saber, a boa disposição para com o próximo, o afinamento das emoções, a capacidade de penetrar nos problemas da vida, o senso de beleza, a percepção da complexidade do mundo e dos seres, o cultivo do humor. A literatura desenvolve em nós a quota de humanidade na medida em que nos torna mais compreensivos e abertos para a natureza, a sociedade, o semelhante (Candido, 2004, p. 249).

Sendo assim, vista como um bem humanizador, a literatura, ainda de acordo com Candido (2004), é um direito humano, uma vez que ela pertence àquela categoria de bens que não podem ser negados a ninguém. Nesse sentido, é preciso defender a necessidade da leitura literária não só porque inúmeros jovens e adultos gostam de ler, mas também porque a literatura é uma das profundas necessidades humanas, necessidade que, se não satisfeita, pode causar a desorganização pessoal ou a frustração mutiladora.

Também não há novidade em dizer que a poesia ocupa um lugar à margem no cenário escolar, visto que os docentes a veem como difícil e, por isso, recusam-se a trabalhar com ela ou, quando o fazem, se valem de uma perspectiva muito mais "gramatiqueira", e o que poderia ser um encontro de estesias torna-se desculpa para a verificação de certa taxionomia gramatical. Entretanto, a experiência estética, advinda do contato com a poesia, propicia ao leitor uma gama de sentimentos que, gestados e desvendados pela criação poética, libertam o sujeito de uma teia de preconceitos e utilitarismos "que, como dados de sua experiência diária, clamam por sua superação" (Osakabe, 2005, p. 49). Como assinala Osakabe (2005), em uma época em que critérios como utilidade e eficácia se impõem como determinantes dos valores de prestígio, nada mais fecundo, para embasar o exercício crítico e a perspectiva transformadora e para propiciar uma experiência nova na e pela linguagem, do que a poesia, que, assim como toda arte, é dotada do poder de emancipar o sujeito das amarras ideológicas, sociais, religiosas. Apesar disso, a escola ainda permanece, como raras exceções, sem conseguir desenvolver um espaço de vivência significativa a partir da convivência com textos poéticos.

Nesse sentido, talvez a novidade de nosso trabalho esteja em reafirmar o óbvio: a necessidade não apenas da presença da poesia na formação dos alunos do ensino básico, mas a necessidade de um trabalho bem planejado e sistemático com o texto poético em sala de aula. Isso exige, pois, que o professor deixe de lado o medo que a poesia pode lhe causar, enfrente essa esfinge e decifre seus enigmas para que esses possam ser compartilhados com os alunos. Para tanto, precisamos de um docente que seja leitor de poesia e que planeje, de forma cuidadosa, como deve ser a entrada do texto poético em sua sala de aula. Sendo assim, os procedimentos que apresentamos aqui servem apenas como ilustração de um caminho possível para essa entrada. Mas eles são um caminho! Muitos outros podem ser encontrados a partir dos autores que citamos e a partir da criatividade do docente que não precisa temer arriscar-se. A sala de aula é um espaço para experimentações. 
Acreditamos que, mais do que um docente que ensine, a nossa escola precisa de docentes que experimentem formas diversas de ensinar. Outra novidade consiste em chamar a atenção para a importância do enfoque intercultural para as aulas de literatura com vistas à ampliação do horizonte cultural de nossos alunos a partir do contato com textos pertencentes a outras culturas. Em decorrência disso, reiteramos a importância das traduções como elo para o estabelecimento desse intercâmbio cultural nessa era de internacionalização dos saberes. Aqui, uma última observação: no trabalho com textos literários traduzidos, o docente precisa ter o cuidado de saber escolher boas traduções. Isso exige um olhar atento ao que o mercado editorial disponibiliza e que, diante da crescente mundialização do conhecimento, tem nos servido como convite para navegarmos por territórios estranhos bem como para o conhecimento do Outro e, por conseguinte, de nós mesmos.

\section{Referências}

ALVES, José Hélder Pinheiro (2014). Discutindo alternativas na formação de leitores. In: ALVES, José Hélder Pinheiro (Org.). Memórias da Borborema 4: discutindo a literatura e o seu ensino. Campina Grande: Abralic. p. 7-18.

ALVES, José Hélder Pinheiro (2016). Estratégias para o ensino de poesia. In: FERNANDES, Maria Lúcia Outeiro; ANDRADE, Paulo; PERRONE, Charles Andrew (Orgs). Poesia na era da internacionalização dos saberes: circulação, tradução, ensino e crítica no contexto contemporâneo. São Paulo: Acadêmica. p. 207-227.

ANDRADE, Carlos Drummond de (2015). Nova reunião: 23 livros de poesia. São Paulo: Companhia das Letras.

BAGNO, Marcos (2014). Prefácio. In: STREET, Brian. Letramentos sociais: abordagens críticas do letramento no desenvolvimento, na etnografia e na educação. Tradução de Marcos Bagno. São Paulo: Parábola Editorial. p. 13-15.

BARTHES, Roland (2007). Aula: aula inaugural da cadeira de semiologia literária no Colégio de França, pronunciada no dia 7 de janeiro de 1977. Tradução de Leyla Perrone-Moisés. São Paulo: Cultrix.

BORGES, Ana Isabel; NERCOLINI, Marildo José (2002). A (im)possibilidade da tradução cultural. In: CONGRESSO BRASILEIRO DE HISPANISTAS, 2., 8 a 11 out. 2002, Universidade de São Paulo. Proceedings. São Paulo: Associação Brasileira de Hispanistas. Disponível em: < https:/ / bit.ly/2UHcuB2 >. Acesso em 16 abr. 2017.

BUZEN, Clecio (2014). Apresentação. In: STREET, Brian. Letramentos sociais: abordagens críticas do letramento no desenvolvimento, na etnografia e na educação. Tradução de Marcos Bagno. São Paulo: Parábola Editorial. p. 7-11.

CANDAU, Vera Maria (2012). Escola, didática e interculturalidade: desafios atuais. In: CANDAU, Vera Maria (Org.). Didática crítica intercultural: aproximações. Rio de Janeiro, Vozes. p. 107-138.

CANDIDO, Antonio (2004). O direito à literatura. In: CANDIDO, Antonio. Vários escritos. São Paulo: Duas Cidades.

COLOMER, Teresa (2007). Andar entre livros: a leitura literária na escola. Tradução de Laura Sandroni. São Paulo: Global.

COSSON, Rildo (2006). Letramento literário: teoria e prática. São Paulo: Contexto.

DIONÍSIO, Maria de Lourdes (2007). Educação e os estudos atuais sobre letramento. Perspectiva, Florianópolis, v. 25, n. 1, p. 209-224, jan./jun.

ECO, Umberto (2003). Sobre a literatura. Tradução de Eliana Aguiar. Rio de Janeiro: Rocco.

JUSTINO, Luciano Barbosa (2014). Literatura de multidão e intermidialidade: ensaios sobre ler e escrever o presente. Campina Grande: Eduepb.

LAJOLO, Marisa (1999). Do mundo da escrita para a leitura do mundo. São Paulo: Ática. 
LEIBRANDT, Isabella (2006). El aprendizaje intercultural a través de la literatura. Revista Espéculo, n. 32, mar/jun. Disponível em: http://www.ucm.es/info/especulo/numero32/aprendiz.html. Acesso em: 14 fev. 2019.

OSAKABE, Haquira. Poesia e indiferença (2005). In: PAIVA, Aparecida et al. (Orgs.). Leituras literárias: discursos transitivos. Belo Horizonte: Autêntica.

OUTINOFF, Michaël (2011). Tradução: história, teorias e métodos. Tradução de Marcos Marcionillo. São Paulo: Parábola.

PAVIS, Patrice (2015). O teatro no cruzamento das culturas. São Paulo: Perspectiva.

PUGLIESE, Adriana; MARANDINO, Martha (2018). Museu como espaço legítimo na formação docente em ciências naturais. In: COSTA, Váldina Gonçalves; BARBOSA, Marinalva Vieira (Orgs.). Formação de professores e contextos de trabalho: diferentes olhares. São Paulo: Mercado de Letras. p. 119-134.

ROJO, Roxane (2009). Letramentos múltiplos, escola e inclusão social. São Paulo: Parábola.

SANTOS, José Luiz (1986). O que é cultura. São Paulo: Brasiliense.

STREET, Brian (2014). Letramentos sociais: abordagens críticas do letramento no desenvolvimento, na etnografia e na educação. Tradução de Marcos Bagno. São Paulo: Parábola.

SZYMBORSKA, Wisława (2011). Poemas. Seleção, tradução e prefácio de Regina Przybycien. São Paulo: Companhia das Letras.

XIDIEH, Oswaldo Elias (1976). Cultura popular. In: XIDIEH, Oswaldo Elias et al. Feira Nacional de cultura popular. São Paulo: SESC. p. 01-06.

ZUMTHOR, Paul (1997). Introdução à poesia oral. Tradução de Jerusa P. Ferreira. São Paulo: Hucitec. 